\title{
Characterization of Phytophthora infestans populations of southern Brazil in 2004 and 2005
}

\author{
Flávio Martins Santana • Cesar Bauer Gomes • \\ Cesar Rombaldi • Valmor João Bianchi • Ailton Reis
}

Received: 25 January 2013 / Accepted: 3 June 2013 /Published online: 26 June 2013

(C) Springer Science+Business Media Dordrecht 2013

\begin{abstract}
The populations of Phytophthora infestans (Pi) in southern Brazil in 2004 and 2005 are characterized herein. The isolates were collected from potato and tomato plants in the states of Paraná (PR), Santa Catarina (SC), and Rio Grande do Sul (RS). The mating type of 131 potato and 32 tomato isolates was determined. Forty-nine isolates from potatoes and 11 from tomatoes were analyzed for their Gpi phenotype. A subset of 35 isolates was evaluated for mitochondrial (mtDNA) polymorphisms. A sample of 146 isolates was tested for sensitivity to the fungicide metalaxyl, and most isolates (64\%) were moderately sensitive. Fiftynine isolates were classified as A1 mating type and 103 as A2. One isolate behaved as both A1 and A2 mating type. All tomato isolates were A1 mating type and presented the 86/100 pattern for the enzyme GPI and
\end{abstract}

F. M. Santana

PPG Fitossanidade, Universidade Federal de Pelotas

(UFPel), 96010-900 Pelotas, RS, Brazil

\section{B. Gomes}

Laboratorio de Fitopatologia, Embrapa Clima Temperado, 96010-970, Pelotas, RS, Brazil

C. Rombaldi

Laboratório de Tecnologia de Alimentos, UFPel, 96001-970, Pelotas, RS, Brazil
mtDNA Ib, indicating that these isolates belong to the US- 1 clonal lineage. Of the 131 potato isolates, 103 were A2, 27 were $\mathrm{A} 1$ and one was A1/A2 mating type. Among the potato isolates 27 exhibited the Gpi phenotype $100 / 100$, the same as BR-1, and 20 were $86 / 100$, the same as US-1. Potato isolates presented the mitochondrial haplotypes Ia (74\%) and IIa (26\%). The data suggest the presence of only the BR-1 clonal lineage on potatoes in the states of PR and SC. However, in the state of RS, more than one clonal lineage was observed infecting potatoes, and there may be sexual reproduction between the lineages.

Keywords Late blight · Pathogen characterization · Population genetics · Solanum lycopersicum $\cdot$ Solanum tuberosum
V. J. Bianchi

Laboratório de Botânica, UFPel, 96001-970 Pelotas, RS, Brazil

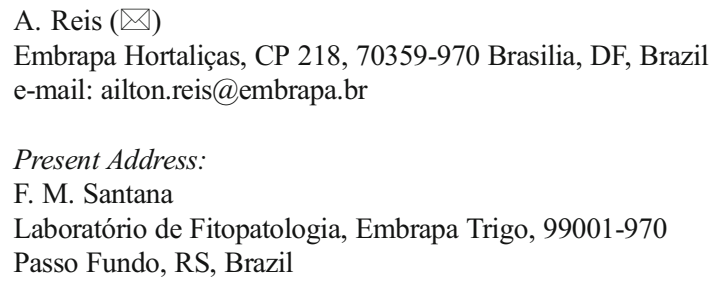




\section{Introduction}

The potato (Solanum tuberosum L.) and tomato (S. lycopersicum L.) are the two most cultivated and consumed vegetables in Brazil. Because they are closely related species, several pathogens attack both of these crops. Among these pathogens, Phytophthora infestans (Mont.) De Bary, the causal agent of late blight, is one of the most important. This disease is widely known to be a limiting factor for the production of tomatoes and potatoes in Brazil (Mizubuti 2001). Under conditions of high humidity and mild temperatures, $P$. infestans can completely devastate a field of crops (Jones et al. 1991; Stevenson et al. 2001).

The species $P$. infestans is heterothallic, and until the early 1980s, isolates of mating type A2 were found only in Mexico (Gallegly \& Galindo 1958). Thus, in all studies conducted until the beginning of the 1980s, only strains of group A1, characterized as the US-1 clonal lineage, were found on cultures of potatoes and tomatoes (Goodwin et al. 1994). After the detection of A2 isolates, initially in Switzerland in 1984 (Hohl \& Iselin 1984), new surveys were conducted, and the presence of the A2 group was observed in several countries in Europe and the Americas (Fry et al. 1992; Fry \& Goodwin 1997; Goodwin et al. 1994). The presence of both mating types in a particular country may enable individuals to meet and mate in the field. Sexual reproduction between isolates of $P$. infestans can lead to the development of new, more diverse populations of pathogens that, consequently, have the potential to cause greater damage to crops of potatoes and tomatoes (Fry \& Goodwin 1997; Goodwin 1997; Ristaino 2002).

In previous studies performed in Brazil, isolates of both mating types of $P$. infestans (A1 and A2) were found (S.H. Brommonschenkel, 1988, MSc thesis, Univ. Federal de Vicosa, Brazil; Reis et al. 2003, 2006). Only strains of group A1, classified as the US-1 clonal lineage, were found associated with tomato crops. Most isolates collected on potato fields were of the A2 mating type and were classified as the BR-1 clonal lineage (Goodwin et al. 1994; Reis et al. 2003). A clonal lineage is composed of isolates descending from one single genotype by asexual reproduction. Identification of one clonal lineage is based on markers, including DNA fingerprinting, mating type, isozymes, resistance to metalaxyl, and mitochondrial DNA patterns (Fry et al. 1992; Goodwin et al. 1994).
It has been observed that, in Brazil, there is not the constant association of a clonal lineage with resistance to the fungicides metalaxyl or mefenoxan (Reis et al. $2003,2005,2006)$. In a study of 258 isolates collected in the southern and southeastern regions of Brazil, isolates of both clonal lineages were found that were resistant, intermediate and sensitive. Therefore, it was not possible to differentiate the clonal lineage US-1 from BR-1 based on metalaxyl resistance (Reis et al. 2005). A specialization of the two clonal lineages to their plant host was also observed. The clonal lineage US-1 was highly aggressive to tomato and less aggressive to potato, whereas the clonal lineage BR-1 was highly aggressive to potato and slightly aggressive to tomato (Suassuna et al. 2004).

Despite the existence of earlier works characterizing $P$. infestans isolates in Brazil, there is a need for constant monitoring of the pathogen population. Knowledge of the genetic structure and the sensitivity to fungicides of the current $P$. infestans population is essential for planning the management of late blight for potatoes and tomatoes. Thus, the aim of the present study was to determine the mating type, the polymorphism of the Gpi allozyme, the mitochondrial DNA haplotypes and the sensitivity to the fungicide metalaxyl of $P$. infestans isolates from southern Brazil, in order to test the hypothesis that the population of this pathogen in the southern region of Brazil is still clonal.

\section{Materials and methods}

Collection of Phytophthora infestans isolates In 2004 and 2005, we collected potato plants with symptoms of late blight from fields in 28 municipalities of the Rio Grande do Sul (RS), Santa Catarina (SC) and Paraná (PR) states (Fig. 1). Most of the collection points were georeferenced by GPS (Table 1). In addition, samples of tomato plants with late blight symptoms were collected in SC state. One to seven isolates were sampled from producing fields, most often one or two, and one to five potato fields and one to eight tomato fields were visited in each municipality during each year. A total of 66 potato fields and 11 tomato fields were sampled in the two years. From samples of the leaves, stems and tubers of potato and tomato plants infected with $P$. infestans, monosporic (one 


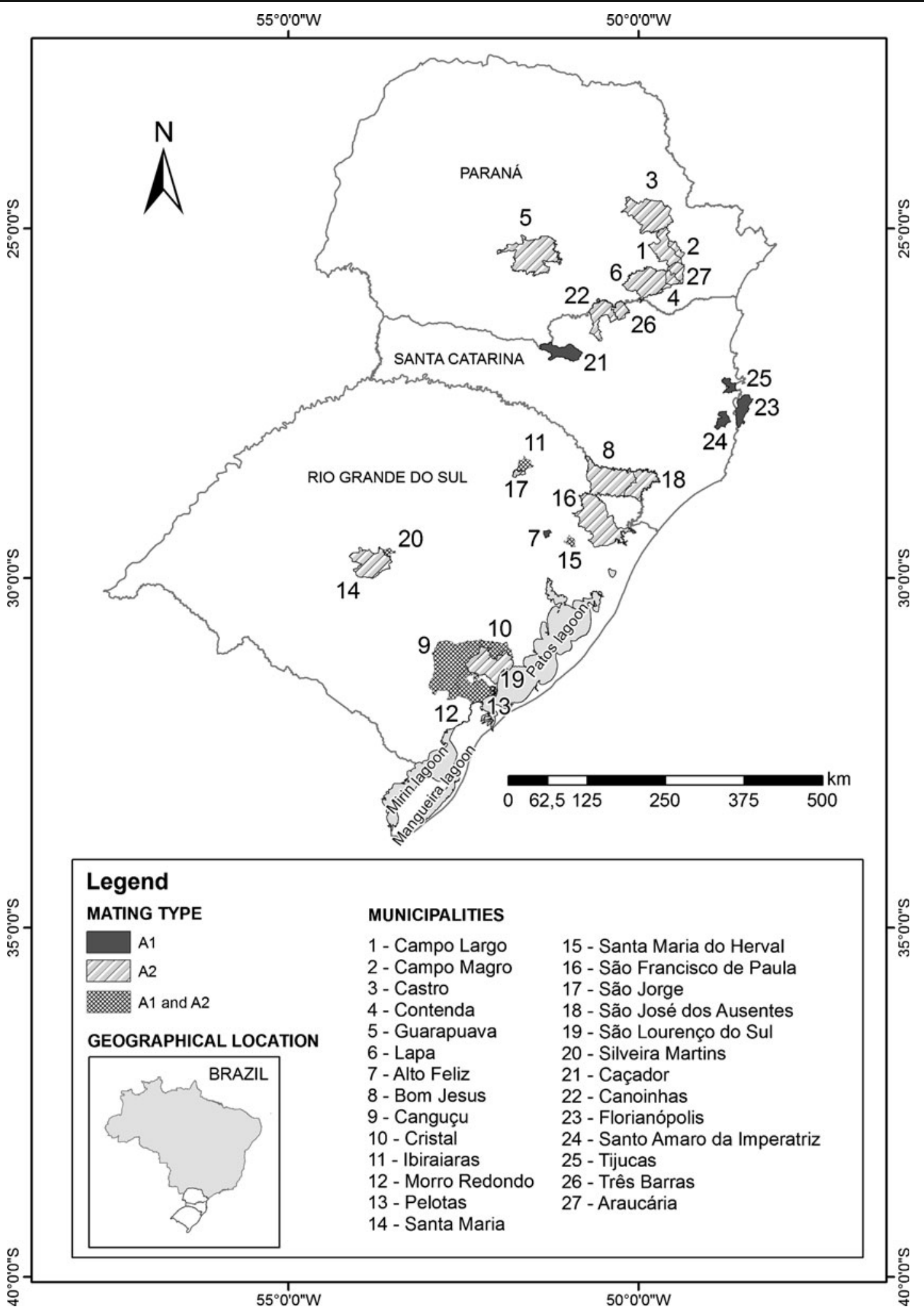

Fig. 1 Sampled areas and distribution of mating type A1 (black areas), A2 (striped areas) and of both A1 and A2 (dotted areas) of Phytophthora infestans in the three states of the southern region of Brazil 
Table 1 Host, origin, mating type and metalaxyl sensitivity of Phytophthora infestans isolates collected in the southern states of Brazil: Parana (PR), Santa Catarina (SC) and Rio Grande do Sul (RS), in the years 2004 and 2005

\begin{tabular}{|c|c|c|c|c|c|c|c|c|}
\hline Isolates & Host & City & State & Year & Latitude & Longitude & Mating Type & Metalaxyl \\
\hline Pi-001, 002 & Potato & Araucária & PR & 2004 & -49 28'09”' & $-2533^{\prime} 54^{\prime \prime}$ & $\mathrm{A}_{2}$ & $\mathrm{~S}$ \\
\hline $\mathrm{Pi}-003$ to 005 & Potato & Araucária & PR & 2004 & $-4930 ' 05^{\prime \prime}$ & $-2535^{\prime} 29 ”$ & $\mathrm{~A}_{2}$ & $\mathrm{~S}$ \\
\hline Pi-007 & Potato & Araucária & PR & 2004 & $-4931 ' 11 ”$ & $-2536^{\prime} 38^{\prime \prime}$ & $\mathrm{A}_{2}$ & $\mathrm{~S}$ \\
\hline Pi-008 & Potato & Contenda & PR & 2004 & $-49300^{\prime} 15^{\prime \prime}$ & -25 40’03”' & $\mathrm{A}_{2}$ & $\mathrm{~S}$ \\
\hline $\mathrm{Pi}-009$ to 015 & Potato & Lapa & PR & 2004 & $-4945^{\prime} 31 ”$ & $-2546^{\prime} 46^{\prime \prime}$ & $\mathrm{A}_{2}$ & S (6), MR (1) \\
\hline Pi-016, 017 & Potato & Lapa & PR & 2004 & -4948 ' $19{ }^{\prime \prime}$ & $-2541^{\prime} 32^{\prime \prime}$ & $\mathrm{A}_{2}$ & $\mathrm{~S}$ \\
\hline Pi-018 & Potato & Campo Largo & PR & 2004 & -49 30’ $50 ”$ & $-2525^{\prime} 09^{\prime \prime}$ & $\mathrm{A}_{2}$ & MR \\
\hline Pi-019, 020 & Potato & Campo Largo & PR & 2004 & $-4930^{\prime} 40^{\prime \prime}$ & -25 25'07”' & $\mathrm{A}_{2}$ & $\mathrm{~S}$ \\
\hline $\mathrm{Pi}-021$ & Potato & Canoinhas & $\mathrm{SC}$ & 2004 & $-4943 ’ 39 ”$ & $-2604^{\prime} 05^{\prime \prime}$ & $\mathrm{A}_{2}$ & $\mathrm{~S}$ \\
\hline Pi-022 to 024 & Potato & Canoinhas & $\mathrm{SC}$ & 2004 & $-5021^{\prime} 49^{\prime \prime}$ & $-2611^{\prime} 28^{\prime \prime}$ & $\mathrm{A}_{2}$ & $\mathrm{~S}$ \\
\hline $\mathrm{Pi}-025$ & Potato & Três Barras & $\mathrm{SC}$ & 2004 & $-5016^{\prime} 39^{\prime \prime}$ & $-2610^{\prime} 51^{\prime \prime}$ & $\mathrm{A}_{2}$ & $\mathrm{~S}$ \\
\hline Pi-026, 027 & Potato & Três Barras & $\mathrm{SC}$ & 2004 & $-5016^{\prime} 42^{\prime \prime}$ & $-2610^{\prime} 50^{\prime \prime}$ & $\mathrm{A}_{2}$ & $\mathrm{~S}$ \\
\hline $\mathrm{Pi}-028$ & Potato & Canoinhas & $\mathrm{SC}$ & 2004 & $-5033^{\prime} 21^{\prime \prime}$ & $-2604^{\prime} 46^{\prime \prime}$ & $\mathrm{A}_{2}$ & $\mathrm{~S}$ \\
\hline Pi-029, 030 & Potato & Canoinhas & $\mathrm{SC}$ & 2004 & $-5033^{\prime} 16^{\prime \prime}$ & $-2604^{\prime} 47^{\prime \prime}$ & $\mathrm{A}_{2}$ & $\mathrm{~S}$ \\
\hline Pi-031 & Potato & Canoinhas & $\mathrm{SC}$ & 2004 & $-5033^{\prime} 22^{\prime \prime}$ & $-2604^{\prime} 45^{\prime \prime}$ & $\mathrm{A}_{2}$ & $\mathrm{~S}$ \\
\hline Pi-032 to 035 & Potato & Canoinhas & $\mathrm{SC}$ & 2004 & -5032 ' $51^{\prime \prime}$ & $-2604^{\prime} 56^{\prime \prime}$ & $\mathrm{A}_{2}$ & $\mathrm{~S}$ \\
\hline $\mathrm{Pi}-036$ to 41 & Potato & Campo Magro & PR & 2004 & $-4922{ }^{\prime} 54^{\prime \prime}$ & $-2522^{\prime} 52^{\prime \prime}$ & $\mathrm{A}_{2}$ & $\mathrm{~S}$ \\
\hline Pi-042, 043 & Potato & Campo Magro & PR & 2004 & $-4925^{\prime} 40^{\prime \prime}$ & $-2523^{\prime} 09^{\prime \prime}$ & $\mathrm{A}_{2}$ & MR, S \\
\hline $\mathrm{Pi}-044$ to 047 & Potato & Campo Magro & PR & 2004 & $-4925^{\prime} 37^{\prime \prime}$ & $-25211^{\prime} 49 ”$ & $\mathrm{~A}_{2}$ & $\mathrm{~S}(3), \mathrm{MR}(1)$ \\
\hline Pi-048 to 050 & Potato & Pelotas & $\mathrm{RS}$ & 2004 & $-5231^{\prime} 28^{\prime \prime}$ & $-3136^{\prime} 39^{\prime \prime}$ & $\mathrm{A}_{2}$ & $\mathrm{~S}$ \\
\hline Pi-051 to 053 & Potato & Morro Redondo & $\mathrm{RS}$ & 2004 & $-5236^{\prime} 30^{\prime \prime}$ & $-3134^{\prime} 17^{\prime \prime}$ & $\mathrm{A}_{2}$ & $\mathrm{~S}$ \\
\hline $\mathrm{Pi}-054$ to 057 & Potato & Canguçu & $\mathrm{RS}$ & 2004 & $-5243^{\prime} 31^{\prime \prime}$ & $-31322^{\prime} 02 ”$ & $A_{2}(3), A_{1}(1)$ & $\mathrm{S}$ \\
\hline $\mathrm{Pi}-058$ to 060 & Potato & Canguçu & $\mathrm{RS}$ & 2004 & $-5244^{\prime} 56^{\prime \prime}$ & $-3133^{\prime} 05^{\prime \prime}$ & $\mathrm{A}_{2}$ & ND (2), S (1) \\
\hline Pi-061, 062 & Potato & Pelotas & $\mathrm{RS}$ & 2004 & $-5235^{\prime} 05^{\prime \prime}$ & $-3126^{\prime} 27^{\prime \prime}$ & $\mathrm{A}_{2}$ & ND \\
\hline $\mathrm{Pi}-063$ to 065 & Potato & Pelotas & $\mathrm{RS}$ & 2004 & $-5222^{\prime} 36^{\prime \prime}$ & $-3133^{\prime} 28^{\prime \prime}$ & $\mathrm{A}_{2}$ & $\mathrm{~S}$ \\
\hline $\mathrm{Pi}-066$ & Potato & Pelotas & $\mathrm{RS}$ & 2004 & $-5226^{\prime} 30^{\prime \prime}$ & $-3131 ’ 44 ”$ & $\mathrm{~A}_{1}$ & MR \\
\hline Pi-067 to 069 & Potato & Morro Redondo & $\mathrm{RS}$ & 2004 & $-5228^{\prime} 51^{\prime \prime}$ & $-3134^{\prime} 53^{\prime \prime}$ & $\mathrm{A}_{1}$ & MR (2), S (1) \\
\hline Pi-071 & Potato & Morro Redondo & $\mathrm{RS}$ & 2004 & -52 29’07’' & $-3135^{\prime} 13^{\prime \prime}$ & $\mathrm{A}_{1}$ & MR \\
\hline Pi-072 to 075 & Potato & Morro Redondo & $\mathrm{RS}$ & 2004 & $-5233^{\prime} 27^{\prime \prime}$ & $-3140^{\prime} 25^{\prime \prime}$ & $\mathrm{A}_{2}(1), \mathrm{A}_{1}(3)$ & MR \\
\hline Pi-076 to 078 & Potato & São Lourenço do Sul & $\mathrm{RS}$ & 2004 & -52 54’09”' & $-3140^{\prime} 35^{\prime \prime}$ & $\mathrm{A}_{2}$ & $\mathrm{~S}$ \\
\hline Pi-079 & Potato & Cristal & $\mathrm{RS}$ & 2004 & $-5156^{\prime} 56^{\prime \prime}$ & $-3111^{\prime} 14^{\prime \prime}$ & $\mathrm{A}_{1}$ & $\mathrm{~S}$ \\
\hline $\mathrm{Pi}-080$ & Potato & Cristal & $\mathrm{RS}$ & 2004 & $-5208^{\prime} 05^{\prime \prime}$ & $-3104 ’ 22 ”$ & $\mathrm{~A}_{1}$ & $\mathrm{~S}$ \\
\hline Pi-082, 083 & Potato & Cristal & $\mathrm{RS}$ & 2004 & $-5209^{\prime} 50^{\prime \prime}$ & $-3104^{\prime} 45^{\prime \prime}$ & $\mathrm{A}_{2}$ & $\mathrm{R}, \mathrm{MR}$ \\
\hline Pi-084 & Potato & Cristal & $\mathrm{RS}$ & 2004 & $-5205^{\prime} 13^{\prime \prime}$ & $-3104^{\prime} 16^{\prime \prime}$ & $\mathrm{A}_{1}$ & MR \\
\hline $\mathrm{Pi}-085$ & Potato & Cristal & $\mathrm{RS}$ & 2004 & $-5205^{\prime} 15^{\prime \prime}$ & $-3104 ’ 13 ”$ & $\mathrm{~A}_{1} / \mathrm{A}_{2}{ }^{*}$ & MR \\
\hline Pi-086 & Potato & Silveira Martins & $\mathrm{RS}$ & 2004 & $-5334^{\prime} 56^{\prime \prime}$ & $-2939^{\prime} 53^{\prime \prime}$ & $\mathrm{A}_{2}$ & ND \\
\hline Pi-087 & Potato & Silveira Martins & $\mathrm{RS}$ & 2004 & $-5334^{\prime} 55^{\prime \prime}$ & $-2939^{\prime} 57^{\prime \prime}$ & $\mathrm{A}_{1}$ & MR \\
\hline Pi-088, 089 & Potato & Silveira Martins & $\mathrm{RS}$ & 2004 & $-5333^{\prime} 47^{\prime \prime}$ & $-2940{ }^{\prime} 08^{\prime \prime}$ & $\mathrm{A}_{2}$ & MR \\
\hline $\mathrm{Pi}-090$ & Potato & Santa Maria & $\mathrm{RS}$ & 2004 & $-5341 ' 17^{\prime \prime}$ & $-2928 ' 50 ”$ & $\mathrm{~A}_{1}$ & MR \\
\hline Pi-092 to 094 & Potato & Santa Maria & $\mathrm{RS}$ & 2004 & $-5341^{\prime} 27^{\prime \prime}$ & $-2928^{\prime} 28^{\prime \prime}$ & $A_{1}(1), A_{2}(2)$ & MR \\
\hline Pi-095, 096 & Potato & Santa Maria & $\mathrm{RS}$ & 2004 & $-5342^{\prime} 18^{\prime \prime}$ & $-2930^{\prime} 29^{\prime \prime}$ & $\mathrm{A}_{2}$ & $\mathrm{MR}, \mathrm{S}$ \\
\hline Pi-097, 098 & Potato & Pelotas & $\mathrm{RS}$ & 2004 & $-5231^{\prime} 24 \prime$ & $-3136 ’ 29 ”$ & $\mathrm{~A}_{2}, \mathrm{~A}_{1}$ & MR \\
\hline Pi-099 & Potato & Canguçu & $\mathrm{RS}$ & 2004 & $-5243^{\prime} 00 ”$ & -3132 '06” & $\mathrm{A}_{1}$ & $\mathrm{~S}$ \\
\hline Pi-100, 101 & Potato & Canguçu & $\mathrm{RS}$ & 2004 & $-5243^{\prime} 55^{\prime \prime}$ & $-3131 ’ 52 ”$ & $\mathrm{~A}_{1}, \mathrm{~A}_{2}$ & $\mathrm{~S}$ \\
\hline
\end{tabular}


Table 1 (continued)

\begin{tabular}{|c|c|c|c|c|c|c|c|c|}
\hline Isolates & Host & City & State & Year & Latitude & Longitude & Mating Type & Metalaxyl \\
\hline Pi-103 & Potato & Guarapuava & PR & 2004 & -51 41'39”' & $-2523{ }^{\prime} 15^{\prime \prime}$ & $\mathrm{A}_{2}$ & $\mathrm{~S}$ \\
\hline Pi-105, 106 & Potato & Guarapuava & PR & 2004 & $-5025{ }^{\prime} 13 ”$ & $-2523{ }^{\prime} 55^{\prime \prime}$ & $\mathrm{A}_{2}$ & $\mathrm{~S}$ \\
\hline Pi-108 & Potato & Castro & PR & 2004 & $-49533^{\prime} 45^{\prime \prime}$ & -24 46’04”' & $\mathrm{A}_{2}$ & MR \\
\hline Pi-110 & Potato & Contenda & PR & 2004 & -49 32' 20”' & $-2542^{\prime} 46^{\prime \prime}$ & $\mathrm{A}_{2}$ & MR \\
\hline Pi-111, 112 & Potato & São Jorge & $\mathrm{RS}$ & 2004 & $-5140 ’ 33 ”$ & $-2828^{\prime} 21^{\prime \prime}$ & $\mathrm{A}_{2}$ & MR \\
\hline Pi-113 to 115 & Potato & Ibiraiaras & $\mathrm{RS}$ & 2004 & $-5136^{\prime} 20^{\prime \prime}$ & $-28200^{\prime} 35^{\prime \prime}$ & $\mathrm{A}_{2}$ & MR \\
\hline Pi-123 & Potato & Alto Feliz & $\mathrm{RS}$ & 2004 & $-51188^{\prime} 47^{\prime \prime}$ & -29 20’39” & $\mathrm{A}_{1}$ & $\mathrm{~S}$ \\
\hline Pi-127 & Tomato & Florianópolis & $\mathrm{SC}$ & 2004 & $\mathrm{DNC}$ & $\mathrm{DNC}$ & $\mathrm{A}_{1}$ & $\mathrm{R}$ \\
\hline Pi-128 & Tomato & Santo Amaro & $\mathrm{SC}$ & 2005 & DNC & $\mathrm{DNC}$ & $\mathrm{A}_{1}$ & $\mathrm{R}$ \\
\hline Pi-129 & Tomato & Tijucas & $\mathrm{SC}$ & 2005 & DNC & $\mathrm{DNC}$ & $\mathrm{A}_{1}$ & $\mathrm{~S}$ \\
\hline Pi-130, 131 & Tomato & Caçador & $\mathrm{SC}$ & 2005 & -50 59’ 46”' & $-2650 ’ 32 ”$ & $\mathrm{~A}_{1}$ & ND \\
\hline Pi-132, 133 & Tomato & Caçador & $\mathrm{SC}$ & 2005 & $-5100 ’ 15^{\prime \prime}$ & $-2651^{\prime} 13 ”$ & $\mathrm{~A}_{1}$ & $\mathrm{~S}$ \\
\hline Pi-134, 135 & Tomato & Caçador & $\mathrm{SC}$ & 2005 & $-5102 ’ 33 ”$ & $-2645^{\prime} 09^{\prime \prime}$ & $\mathrm{A}_{1}$ & $\mathrm{~S}, \mathrm{ND}$ \\
\hline $\mathrm{Pi}-136$ to 140 & Tomato & Caçador & $\mathrm{SC}$ & 2005 & -51 04’06” & $-2644^{\prime} 44 ”$ & A1 & $\mathrm{S}(2), \mathrm{ND}(3)$ \\
\hline Pi-141 to 146 & Tomato & Caçador & $\mathrm{SC}$ & 2005 & $-5103^{\prime} 25^{\prime \prime}$ & $-2647^{\prime} 28^{\prime \prime}$ & $\mathrm{A}_{1}$ & MR (5), S (1) \\
\hline Pi-147, 148 & Potato & Santa Maria do Herval & $\mathrm{RS}$ & 2005 & $-5055^{\prime} 56^{\prime \prime}$ & $-2928{ }^{\prime} 19 ”$ & $\mathrm{~A}_{2}$ & MR \\
\hline Pi-149 & Potato & Santa Maria do Herval & $\mathrm{RS}$ & 2005 & $-5056^{\prime} 13^{\prime \prime}$ & $-29277^{\prime} 15^{\prime \prime}$ & $\mathrm{A}_{1}$ & MR \\
\hline Pi-150 & Potato & Santa Maria do Herval & $\mathrm{RS}$ & 2005 & $-5059^{\prime} 41^{\prime \prime}$ & $-2926^{\prime} 01^{\prime \prime}$ & $\mathrm{A}_{1}$ & MR \\
\hline Pi-151 to 153 & Potato & Santa Maria do Herval & $\mathrm{RS}$ & 2005 & $-5101 ’ 32 ”$ & $-2929 ’ 31 ”$ & $\mathrm{~A}_{1}(2), \mathrm{A} 2(1)$ & $\mathrm{S}(1), \mathrm{MR}(2)$ \\
\hline Pi-154, 155 & Potato & Santa Maria do Herval & $\mathrm{RS}$ & 2005 & $-5056^{\prime} 42^{\prime \prime}$ & $-2931^{\prime} 34 \prime$ & $\mathrm{A}_{2}$ & MR, S \\
\hline Pi-156 to 158 & Potato & Sao Francisco de Paula & $\mathrm{RS}$ & 2005 & $-5027 ' 36 ”$ & $-2923{ }^{\prime} 58^{\prime \prime}$ & $\mathrm{A}_{2}$ & S (2), MR (1) \\
\hline Pi-159, 160 & Potato & Sao Francisco de Paula & $\mathrm{RS}$ & 2005 & $-5027^{\prime} 24^{\prime \prime}$ & $-2924^{\prime} 20^{\prime \prime}$ & $\mathrm{A}_{2}$ & $\mathrm{~S}$ \\
\hline Pi-162 & Potato & Sao Francisco de Paula & $\mathrm{RS}$ & 2005 & $-5025^{\prime} 55^{\prime \prime}$ & $-2923 ’ 12 ”$ & $\mathrm{~A}_{2}$ & MR \\
\hline Pi-164, 165 & Potato & Sao Jose dos Ausentes & $\mathrm{RS}$ & 2005 & -50 09’ 19”' & $-2900 ’ 37 ’$ & $\mathrm{~A}_{2}$ & $\mathrm{~S}$ \\
\hline Pi-166 & Potato & Sao Jose dos Ausentes & $\mathrm{RS}$ & 2005 & $-5004 ’ 13 ”$ & $-2845^{\prime} 41^{\prime \prime}$ & $\mathrm{A}_{2}$ & $\mathrm{~S}$ \\
\hline Pi-169 & Potato & Sao Jose dos Ausentes & $\mathrm{RS}$ & 2005 & $-5023^{\prime} 58^{\prime \prime}$ & $-2839^{\prime} 24^{\prime \prime}$ & $\mathrm{A}_{2}$ & ND \\
\hline Pi-170 & Potato & Bom Jesus & $\mathrm{RS}$ & 2005 & $-5033^{\prime} 52^{\prime \prime}$ & $-2838^{\prime} 10^{\prime \prime}$ & $\mathrm{A}_{2}$ & ND \\
\hline Pi-171 & Potato & Ibiraiaras & $\mathrm{RS}$ & 2005 & $-5134^{\prime} 36^{\prime \prime}$ & $-2830^{\prime} 53^{\prime \prime}$ & $\mathrm{A}_{2}$ & MR \\
\hline Pi-172 & Potato & Pelotas & $\mathrm{RS}$ & 2005 & $\mathrm{DNC}$ & $\mathrm{DNC}$ & $\mathrm{A}_{2}$ & $\mathrm{~S}$ \\
\hline Pi-173 & Potato & Pelotas & $\mathrm{RS}$ & 2005 & $\mathrm{DNC}$ & $\mathrm{DNC}$ & $\mathrm{A}_{1}$ & ND \\
\hline Pi-174 to 176 & Tomato & Caçador & $\mathrm{SC}$ & 2005 & $\mathrm{DNC}$ & $\mathrm{DNC}$ & $\mathrm{A}_{1}$ & $\mathrm{~S}$ \\
\hline Pi-177 to 182 & Tomato & Caçador & $\mathrm{SC}$ & 2005 & DNC & $\mathrm{DNC}$ & $\mathrm{A}_{1}$ & MR (4), ND (2) \\
\hline $\mathrm{Pi}-183$ to 186 & Tomato & Caçador & $\mathrm{SC}$ & 2005 & $\mathrm{DNC}$ & $\mathrm{DNC}$ & $\mathrm{A}_{1}$ & MR (3), ND (1) \\
\hline
\end{tabular}

$\mathrm{DNC}=$ Data not collected

$\mathrm{S}=$ sensitive, $\mathrm{MR}=$ moderately resistant, $\mathrm{R}=$ resistant, and $\mathrm{ND}=$ not determined

*Isolate behaving as A1 and A2 mating type

sporangium) isolation of the pathogen in culture was performed (Forbes et al. 1997).

Mating type determination All isolates were paired with known A1 (US-1) and A2 (BR-1) tester isolates on $10 \%$ clarified V8 juice agar. Mycelial plugs (12 mm diameter) of a known A1 or A2 isolate were placed on opposite sides of the strip of the unknown isolate. A strip (5-6 mm width $\mathrm{x} 40-50 \mathrm{~mm}$ length) of culture medium containing mycelial growth of a 7-10day-old isolate was centered in the plate $(90 \mathrm{~mm}$ diameter) between the two discs. The plates were 
transferred into an incubator at $18^{\circ} \mathrm{C}$. After incubation for 3-4 weeks in the dark, the plates were checked microscopically for the presence of oospores where the mycelia of the known and unknown isolates intermingled. Isolates that produced oospores when paired with the A1 tester isolate but did not produce oospores with the A2 isolate were designated A2. Isolates that formed oospores when paired with the A2 tester but did not form oospores when paired with the A1 isolate were designated A1. Additionally, to confirm the mating type, 15 isolates from the different regions were analyzed by PCR using the primers S1A and S1B. These primers amplify a fragment of DNA of approximately 1,250 bp corresponding to locus S1, which is linked to the A1-determining allele of the mating type locus (Judelson 1996). The reaction was performed as described by Judelson (1996). As controls, DNA from A1 (US-1) and A2 (BR-1) mating type isolates (positive control) and water (negative control) were used.

Gpi pattern The Gpi genotypes of 60 isolates were determined by $6 \%$ bis-acrylamide gel electrophoresis. Mycelia for allozyme analysis were obtained from cultures grown in $50 \mathrm{ml}$ of pea broth for 10 days. The fungal mycelia were macerated in enzyme buffer. Pieces of filter paper $(1 \times 5 \mathrm{~mm})$ were moistened in the macerated mycelia and applied to the gel. The migration conditions were $120 \mathrm{~V}$ for $3 \mathrm{~h}$ with a distance of 12 $\mathrm{cm}$ between the electrodes. To stain the gel, $50 \mathrm{ml}$ of 0.1 M Tris, $0.5 \mathrm{ml}$ of $1 \mathrm{M} \mathrm{MgCl}_{2} 6 \mathrm{H}_{2} \mathrm{O}, 40 \mathrm{mg}$ of fructose 6-phosphate, $10 \mathrm{mg}$ of NADP +, $10 \mathrm{mg}$ of MTT, $2 \mathrm{mg}$ of PMS and 20 units of glucose 6-phosphate isomerase were used. The visualization of the bands was performed after the gel was incubated at $37^{\circ} \mathrm{C}$ for $1 \mathrm{~h}$. The relative mobility of the polymorphic bands was calculated as the ratio between the migration of the alleles of each enzyme individually and the migration of the most frequent allele, which was assigned a value of 100 (Forbes et al. 1998). As a control, one US-1 isolate that was collected in Brasilia-DF and that had a 86/100 Gpi pattern, was used.

Mitochondrial haplotypes Based on the mating type and Gpi data, a subset of 35 isolates was chosen for the mitochondrial DNA analysis. Polymorphism of the mitochondrial DNA was accessed by analyzing for the haplotypes established by Carter et al. (1990). DNA extraction and the determination of the four known mitochondrial haplotypes of $P$. infestans were performed according to Griffith \& Shaw (1998). The mitochondrial haplotypes of the tested strains were determined by comparing their patterns to the reference isolates US-1 (Ib) and BR-1 (IIa).

Metalaxyl sensitivity A sample of 146 isolates was characterized for sensitivity to the fungicide metalaxyl on rye-B agar media as described elsewhere (Deahl et al. 1993; Therrien et al. 1993). A 10-mm-diam mycelial plug from a 9-day-old colony was placed in the center of a petri dish containing rye-B supplemented with 5 or 100 ppm metalaxyl (Apron 350, Syngenta Co., Greensboro, NC, USA). Control plates contained rye-B medium with no metalaxyl (0 ppm). Three replicates of each metalaxyl concentration for each isolate were used. The plates were maintained at $16^{\circ} \pm 1^{\circ} \mathrm{C}$ in the dark. The colony diameter was measured after 14 days, when the diameter of the colony grown at 0 ppm concentration was at least $30 \mathrm{~mm}$. The diameter of the colony was corrected for the diameter of the initial mycelial plug. The mean colony diameters of both plates at 5 and 100 ppm of metalaxyl were divided by the mean colony diameter of the control plates to determine the relative growth. Isolates that grew to a size that was less than $40 \%$ of the size of the control on 5 and $100 \mathrm{ppm}$ metalaxyl plates were recorded as sensitive. Isolates that grew to a size of more than $40 \%$ of the size of the control on 5 ppm metalaxyl medium and less than $40 \%$ of the size of the control on $100 \mathrm{ppm}$ metalaxyl medium were recorded as intermediately resistant. Isolates that grew to a size of more than $40 \%$ of the size of the control on both 5 and 100 ppm metalaxyl medium were recorded as resistant (Therrien et al. 1993).

\section{Results}

In the main potato and tomato producing areas of the three southern Brazilian states, 162 isolates of $P$. infestans were collected: 36 potato isolates in $\mathrm{PR}, 15$ in $\mathrm{SC}$, and 80 in RS, and 31 tomato isolates in SC (Table 1). All potato isolates of $P$. infestans collected in PR and SC belonged to the A2 mating type. It was also observed that all tomato isolates from $\mathrm{SC}$ belonged to the A1 mating type. However, in RS, we found isolates behaving as A1 (33.75\%), A2 (65\%) and as both A1/A2 (1.25\%) mating types infecting potatoes (Table 1). In 2004 and 2005, 
isolates of mating types $\mathrm{A} 1$ and $\mathrm{A} 2$ were found on potatoes in almost all the sampled regions in RS.

Sometimes, isolates of both A1 and A2 mating types were collected on the same property but in different crop fields, and sometimes the two types were found in the same field, as in the municipalities of Canguçu, Morro Redondo, Santa Maria and Pelotas in 2004 and in Santa Maria Herval in 2005 (Table 1). The PCR analysis of selected isolates from the three states revealed the presence of a $1.35 \mathrm{~kb}$ band in the A1 isolates, and the absence of this band in A2 isolates.

Two phenotypes were detected for the enzyme Gpi among $P$. infestans isolates in southern Brazil (Table 2). Isolates from tomato plants showed a single phenotype for $G p i, 86 / 100$, which is the same as the US- 1 clonal lineage (Goodwin et al. 1994). Isolates from potato plants collected in the states of PR and SC exhibited only the phenotype 100/100, which is the same Gpi as the BR-1 clonal lineage. However, in the state of RS, there were two Gpi phenotypes in isolates from potato plants, of which 20 (54\%) were 86/100 and 17 (46\%) were $100 / 100$. Furthermore, there were A1 and A2 isolates within both the 100/100 and 86/100 Gpi phenotypes (Table 2), suggesting the presence of more than one clonal lineage among the isolates from potato plants in RS or even the occurrence of a sexually reproducing population.

Three mitochondrial haplotypes were found in $P$. infestans populations from southern Brazil. On tomato plants, we found only haplotype Ib. On potato crops in the states of PR and SC, we observed only the mitochondrial haplotype IIa. However, in Rio Grande do Sul state there were two mitochondrial haplotypes in isolates of $P$. infestans from potato plants. The mitochondrial haplotype IIa, which had been detected previously in Brazil and the Ia haplotype, which had not yet been reported in Brazil, were found. Among the isolates from potato plants in RS, there were some combinations of these mitochondrial haplotypes with two patterns of $G P i$ phenotypes and the two mating types, such as A1 x 100/100 x Ia, A2 x 100/100 x Ia and IIa, and A2 x 86/100 x Ia and IIa. Taking into account the three markers - mating type, Gpi phenotype and the mitochondrial haplotypes - at least eight multilocus genotypes were detected in this study in the P. infestans populations in southern Brazil (Table 3).

Most $P$. infestans isolates were sensitive to metalaxyl $(90=61.6 \%)$, a smaller group of isolates was intermediately resistant $(53=36.3 \%)$, and only three isolates $(2.1 \%)$ were resistant. Just one potato isolate was resistant $(0.8 \%)$, whereas $42(34.2 \%)$ were intermediate, and $80(65.0 \%)$ were sensitive. Of the tomato plants, two $(8.7 \%)$ isolates were resistant, 11 were intermediate $(47.8 \%)$, and $10(43.5 \%)$ were sensitive.

\section{Discussion}

This work is part of a continuing effort by EMBRAPA Plant Pathologists to monitor and understand the population structure of $P$. infestans on potato and tomato plants in Brazil. The knowledge of pathogen population structure and dynamics is useful in determining the most appropriate integrated management strategies for the control of potato and tomato late blight. Of particular interest is testing for sexual reproduction and its implications for pathogen virulence/aggressiveness and resistance to fungicides. Our hypothesis that the southern Brazil population of $P$. infestans is still clonal is true for the pathogen population on tomatoes and the ones on potatoes in the states of PR and SC. However, analyzing the multilocus genotypes detected among the isolates from potato in RS, there is evidence of a mating population of $P$. infestans attacking potatoes in this state.

The mating types A1 and A2 of P. infestans found on tomato and potato, respectively, in the states of SC and PR, suggest that the pathogen populations in these Brazilian states remain clonal, as observed previously (S.H. Brommonschenkel 1988, thesis; Reis et al. 2003). However, in RS, the presence of both A1 and A2 isolates leads us to hypothesize the occurrence of sexual reproduction of $P$. infestans on potatoes in this state. If that is so, this can be a concern for potato growers because the occurrence of sexual reproduction in P. infestans can lead to the development of new, more diverse populations of the pathogen that may exhibit increased resistance to fungicides and/or be more virulent or aggressive. This pathogen population, consequently, may have the potential to cause greater damage to host crops (Fry \& Goodwin 1997; Gavino et al. 2000; Goodwin 1997). Furthermore, resistant spores (oospores) can survive for long periods in the soil and serve as an additional source of inoculum, allowing outbreaks of late blight to occur earlier in the season. The PCR analysis of selected isolates from the 
Table 2 Mating type, phenotype for the enzyme glucose-6 phosphate isomerase $(\mathrm{Gpi})$ and mitochondrial haplotypes of Phytophthora infestans isolates collected in the years 2004 and

\begin{tabular}{|c|c|c|c|c|c|}
\hline Isolate & Mating type & Gpi & Haplotype & Host & State of Origin \\
\hline Pi-002 & $\mathrm{A}_{2}$ & $100 / 100$ & IIa & Potato & Paraná \\
\hline Pi-009 & $\mathrm{A}_{2}$ & $\mathrm{ND}^{\mathrm{z}}$ & IIa & Potato & Paraná \\
\hline Pi-011 & $\mathrm{A}_{2}$ & $100 / 100$ & ND & Potato & Paraná \\
\hline Pi-018 & $\mathrm{A}_{2}$ & ND & IIa & Potato & Paraná \\
\hline Pi-020 & $\mathrm{A}_{2}$ & $100 / 100$ & ND & Potato & Paraná \\
\hline Pi-021 & $\mathrm{A}_{2}$ & $100 / 100$ & ND & Potato & Santa Catarina \\
\hline Pi-029 & $\mathrm{A}_{2}$ & $100 / 100$ & ND & Potato & Santa Catarina \\
\hline Pi-036 & $\mathrm{A}_{2}$ & $100 / 100$ & ND & Potato & Paraná \\
\hline Pi-046 & $\mathrm{A}_{2}$ & $100 / 100$ & ND & Potato & Paraná \\
\hline Pi-047 & $\mathrm{A}_{2}$ & ND & IIa & Potato & Paraná \\
\hline Pi-056 & $\mathrm{A}_{1}$ & $86 / 100$ & Ia & Potato & Rio Grande do Sul \\
\hline Pi-066 & $\mathrm{A}_{1}$ & $100 / 100$ & ND & Potato & Rio Grande do Sul \\
\hline Pi-068 & $\mathrm{A}_{1}$ & $100 / 100$ & ND & Potato & Rio Grande do Sul \\
\hline Pi-069 & $\mathrm{A}_{1}$ & $100 / 100$ & Ia & Potato & Rio Grande do Sul \\
\hline Pi-069 & $\mathrm{A}_{1}$ & $100 / 100$ & Ia & Potato & Rio Grande do Sul \\
\hline Pi-071 & $\mathrm{A}_{1}$ & $100 / 100$ & ND & Potato & Rio Grande do Sul \\
\hline Pi-072 & $\mathrm{A}_{2}$ & $100 / 100$ & Ia & Potato & Rio Grande do Sul \\
\hline Pi-073 & $\mathrm{A}_{1}$ & $100 / 100$ & Ia & Potato & Rio Grande do Sul \\
\hline Pi-074 & $\mathrm{A}_{1}$ & $100 / 100$ & Ia & Potato & Rio Grande do Sul \\
\hline Pi-075 & $\mathrm{A}_{1}$ & $86 / 100$ & ND & Potato & Rio Grande do Sul \\
\hline Pi-080 & $\mathrm{A}_{1}$ & $86 / 100$ & Ia & Potato & Rio Grande do Sul \\
\hline Pi-082 & $\mathrm{A}_{1}$ & $86 / 100$ & Ia & Potato & Rio Grande do Sul \\
\hline Pi-084 & $\mathrm{A}_{1}$ & $86 / 100$ & ND & Potato & Rio Grande do Sul \\
\hline Pi-085 & $\mathrm{A}_{1} \mathrm{~A}_{2}$ & $86 / 100$ & Ia & Potato & Rio Grande do Sul \\
\hline Pi-087 & $\mathrm{A}_{1}$ & $100 / 100$ & Ia & Potato & Rio Grande do Sul \\
\hline Pi-089 & $\mathrm{A}_{2}$ & $100 / 100$ & ND & Potato & Rio Grande do Sul \\
\hline Pi-090 & $\mathrm{A}_{1}$ & $86 / 100$ & Ia & Potato & Rio Grande do Sul \\
\hline Pi-093 & $\mathrm{A}_{1}$ & $86 / 100$ & Ia & Potato & Rio Grande do Sul \\
\hline Pi-094 & $\mathrm{A}_{2}$ & $86 / 100$ & ND & Potato & Rio Grande do Sul \\
\hline Pi-096 & $\mathrm{A}_{2}$ & $86 / 100$ & ND & Potato & Rio Grande do Sul \\
\hline Pi-098 & $\mathrm{A}_{1}$ & $86 / 100$ & Ia & Potato & Rio Grande do Sul \\
\hline Pi-099 & $\mathrm{A}_{1}$ & $86 / 100$ & ND & Potato & Rio Grande do Sul \\
\hline Pi-100 & $\mathrm{A}_{1}$ & $86 / 100$ & ND & Potato & Rio Grande do Sul \\
\hline Pi-101 & $\mathrm{A}_{2}$ & $100 / 100$ & Ia & Potato & Rio Grande do Sul \\
\hline Pi-103 & $\mathrm{A}_{2}$ & $100 / 100$ & IIa & Potato & Guarapuava-PR \\
\hline Pi-105 & $\mathrm{A}_{2}$ & $100 / 100$ & ND & Potato & Paraná \\
\hline Pi-108 & $\mathrm{A}_{2}$ & $100 / 100$ & IIa & Potato & Paraná \\
\hline Pi-110 & $\mathrm{A}_{2}$ & $100 / 100$ & ND & Potato & Paraná \\
\hline Pi-114 & $\mathrm{A}_{1}$ & $100 / 100$ & ND & Potato & Rio Grande do Sul \\
\hline Pi-115 & $\mathrm{A}_{1}$ & $100 / 100$ & ND & Potato & Rio Grande do Sul \\
\hline Pi-123 & $\mathrm{A}_{1}$ & $100 / 100$ & Ia & Potato & Rio Grande do Sul \\
\hline $\mathrm{Pi}-126^{\mathrm{y}}$ & $\mathrm{A}_{1}$ & $86 / 100$ & $\mathrm{Ib}$ & Tomato & Brasília-DF \\
\hline Pi-128 & $\mathrm{A}_{1}$ & $86 / 100$ & $\mathrm{Ib}$ & Tomato & Santa Catarina \\
\hline
\end{tabular}

2005 in potato and tomato fields in the states of Rio Grande do Sul, Santa Catarina and Paraná, Brazil 
Table 2 (continued)

\begin{tabular}{|c|c|c|c|c|c|}
\hline Isolate & Mating type & $G p i$ & Haplotype & Host & State of Origin \\
\hline Pi-129 & $\mathrm{A}_{1}$ & $86 / 100$ & ND & Tomato & Santa Catarina \\
\hline Pi-130 & $\mathrm{A}_{1}$ & $86 / 100$ & $\mathrm{Ib}$ & Tomato & Santa Catarina \\
\hline Pi-131 & $\mathrm{A}_{1}$ & $86 / 100$ & $\mathrm{Ib}$ & Tomato & Santa Catarina \\
\hline Pi-149 & $\mathrm{A}_{1}$ & $86 / 100$ & ND & Potato & Rio Grande do Sul \\
\hline $\mathrm{Pi}-151$ & $\mathrm{~A}_{2}$ & $100 / 100$ & ND & Potato & Rio Grande do Sul \\
\hline Pi-155 & $\mathrm{A}_{2}$ & $100 / 100$ & ND & Potato & Rio Grande do Sul \\
\hline Pi-156 & $\mathrm{A}_{2}$ & $100 / 100$ & Ia & Potato & Rio Grande do Sul \\
\hline Pi-157 & $\mathrm{A}_{2}$ & $100 / 100$ & Ia & Potato & Rio Grande do Sul \\
\hline Pi-162 & $\mathrm{A}_{2}$ & $86 / 100$ & Ia & Potato & Rio Grande do Sul \\
\hline Pi-166 & $\mathrm{A}_{2}$ & $86 / 100$ & Ia & Potato & Rio Grande do Sul \\
\hline Pi-169 & $\mathrm{A}_{2}$ & $86 / 100$ & Ia & Potato & Rio Grande do Sul \\
\hline Pi-171 & $\mathrm{A}_{2}$ & $86 / 100$ & IIa & Potato & Rio Grande do Sul \\
\hline Pi-172 & $\mathrm{A}_{1}$ & $86 / 100$ & ND & Potato & Rio Grande do Sul \\
\hline Pi-173 & $\mathrm{A}_{1}$ & $86 / 100$ & ND & Potato & Rio Grande do Sul \\
\hline Pi-177 & $\mathrm{A}_{1}$ & $86 / 100$ & $\mathrm{Ib}$ & Tomato & Santa Catarina \\
\hline Pi-179 & $\mathrm{A}_{1}$ & $86 / 100$ & ND & Tomato & Santa Catarina \\
\hline Pi-182 & $\mathrm{A}_{1}$ & $86 / 100$ & $\mathrm{Ib}$ & Tomato & Santa Catarina \\
\hline Pi-183 & $\mathrm{A}_{1}$ & $86 / 100$ & $\mathrm{Ib}$ & Tomato & Santa Catarina \\
\hline Pi-185 & $\mathrm{A}_{1}$ & $86 / 100$ & ND & Tomato & Santa Catarina \\
\hline Pi-186 & $\mathrm{A}_{1}$ & $86 / 100$ & $\mathrm{Ib}$ & Tomato & Santa Catarina \\
\hline
\end{tabular}

${ }^{\mathrm{z}} \mathrm{ND}=$ not determined

${ }^{\mathrm{y}}$ Used as mating type, allozyme and haplotype control

three states confirmed the mating type identity of the isolates, as in Judelson (1996).

The phenotypes for Gpi found in P. infestans isolates in PR and SC reinforce the hypothesis of the presence of only two clonal lineages of the pathogen in these states and they are host specific. Tomato isolates from SC are 86/100, which is the same Gpi of the clonal lineage US-1, whereas the potato isolates from PR and SC are 100/100, which is the same Gpi of the BR-1 clonal lineage. This corroborates the findings of

Table 3 Multilocus genotypes/phenotypes found among isolates of Phytophthora infestans collected in the southern states of Brazil: Parana (PR), Santa Catarina (SC) and Rio Grande do Sul (RS)

\begin{tabular}{|c|c|c|c|c|c|c|}
\hline Genotype & Mating type & Gpi phenotype & Mitochondrial haplotype & Host & State of origin & Probable lineage* \\
\hline 1 & $\mathrm{~A}_{1}$ & $86 / 100$ & Ia & Potato & $\mathrm{RS}$ & $\mathrm{NL} / \operatorname{Rec}$ \\
\hline 2 & $\mathrm{~A}_{1}$ & $100 / 100$ & Ia & Potato & $\mathrm{RS}$ & $\mathrm{NL} / \operatorname{Rec}$ \\
\hline 3 & $\mathrm{~A}_{1} \mathrm{~A}_{2}$ & $86 / 100$ & Ia & Potato & RS & NL/Rec \\
\hline 4 & $\mathrm{~A}_{1}$ & $86 / 100$ & $\mathrm{Ib}$ & Tomato & $\mathrm{SC}$ & US-1 \\
\hline 5 & $\mathrm{~A}_{2}$ & $100 / 100$ & IIa & Potato & RS, PR and SC & BR-1 \\
\hline 6 & $\mathrm{~A}_{2}$ & $100 / 100$ & Ia & Potato & $\mathrm{RS}$ & $\mathrm{NL} / \mathrm{Rec}$ \\
\hline 7 & $\mathrm{~A}_{2}$ & $86 / 100$ & Ia & Potato & $\mathrm{RS}$ & $\mathrm{NL} / \mathrm{Rec}$ \\
\hline 8 & $\mathrm{~A}_{2}$ & $86 / 100$ & IIa & Potato & RS & $\mathrm{NL} / \mathrm{Rec}$ \\
\hline
\end{tabular}

$* \mathrm{NL} / \mathrm{Rec}=$ New lineage or recombinant 
a previous study by Reis et al. (2003). However, in the state of RS, the presence of both mating types, two Gpi phenotypes and the combinations between them in isolates from potato plants is additional evidence of the occurrence of more than one clonal lineage among the isolates from potato plants in $\mathrm{RS}$ or even the occurrence of a sexually reproducing population of the pathogen.

The mitochondrial haplotype $\mathrm{Ib}$, found on tomato in $\mathrm{SC}$, is the same already reported in previous studies (Reis et al. 2003). This finding, along with the mating type and GPi results, confirms that the pathogen population on tomato plants in southern Brazil remains highly uniform and consists only of the old clonal lineage US-1, which is widely distributed in many countries of the world (Fry et al. 1992; Goodwin et al. 1994). On potato crops in the states of PR and SC, we also observed only one mitochondrial haplotype (IIa). This mitochondrial haplotype had already been detected in A2 isolates from the major potato-producing regions of Brazil. These data, along with the mating type and GPi data, also confirm that the $P$. infestans population on potato plants from these two states remains uniform, with the presence of only the clonal lineage BR-1, as observed by Reis et al. (2003).

The results of the characterization of the population of $P$. infestans from potato in RS are in contrast with those from PR and SC. In RS, in addition to two mating types and two patterns of GPi phenotypes, also two mitochondrial haplotypes were found: the mitochondrial haplotype IIa, which had been detected previously in Brazil (Reis et al. 2003); and also the Ia haplotype, which had not yet been reported in Brazil. This mitochondrial haplotype is common in the Andean region (Adler et al. 2004; Garry et al. 2005; Vargas et al. 2009), is widely distributed throughout the world (Gavino \& Fry 2002; Ristaino et al. 2012), and may have been introduced into Brazil by European colonizers. The southern region was the first place where potato was cultivated in Brazil at the end of the $19^{\text {Th }}$ century. At that time it was probably the prevalent mitochondrial haplotype in Europe (Ristaino et al. 2012). Another possibility is a recent introduction through imported seed potatoes from either Europe or North America. Among the isolates from potato plants in RS, there were some combinations of these mitochondrial haplotypes with two patterns of GPi phenotypes and the two mating types. These combinations are interesting when considering that the two mating types and the two allozymes were already present in Brazil. The only new finding here is the haplotype Ia and the combinations it forms with both mating types and allozymes. Because of our limited sample, it is not possible to speculate on the extent to which those combinations occur in nature or whether there are other combinations that were not detected in our samples. Thus, there were differences between the results reported here and those obtained by Reis et al. (2003, 2006) in Brazil and by Deahl et al. (2003) in Uruguay. Those authors observed that the vast majority of isolates from potato plants in both countries presented a unique pattern, with mating type A2, 100/100 GPi and IIa mitochondrial haplotype; these isolates were characterized as BR-1. In the present work it was observed that at least the population of the pathogen in RS changed.

The markers used in this study were not sufficient for determining with precision whether the $P$. infestans population on potatoes in RS is clonal or is reproducing sexually. Now, new work is being carried out using also other markers such as microsatellites (SSR) and single nucleotide polymorphisms (SNPs). They are codominant and permit identification of alleles in both homozygous and heterozygous genotypes (Cooke \& Lees 2004; Cooke et al. 2012). The use of these markers will help us to better understand the complex genetic diversity of populations of $P$. infestans in southern Brazil.

The results obtained in the metalaxyl sensitivity test are in agreement with those of Reis et al. (2005), who found isolates of all three classes of resistance on tomato and potato plants in Brazil. However, in that earlier work, the percentage of resistant isolates from both tomato and potato plants was much higher. One possible explanation for this phenomenon is that metalaxyl is no longer used for the control of late blight in Brazil. Even the use of its $\mathrm{R}$ enantiomer (mefenoxan) has decreased, due to its low efficiency and the use of new commercial blends of several other fungicides or mixtures of fungicides to control late blight.

In conclusion, the current population of $P$. infestans in the southern region of Brazil consists of the clonal lineage $\mathrm{BR}-1$, which is of the mating type $\mathrm{A} 2$, on potato plants in the states of PR and SC. In SC, the $P$. infestans population on tomato plants consists of only one clonal lineage of mating type A1, named US1. These two clonal lineages had already been reported in Brazil in previous studies. However, in the state of 
$\mathrm{RS}$, the pathogen population on potatoes consists of a mixture of different clonal lineages and/or a sexual population. Additionally, resistance to the fungicide metalaxyl in the $P$. infestans population from the southern region of Brazil appears to have decreased. Further analyses using molecular markers, such as RFLP, SSR and SNPs, should reveal whether hybrid populations arising from sexual reproduction are occurring in this region.

Acknowledgment The authors thank CNPq (Brazilian Council for Scientific Research) for the partial funding of this work and for the Ailton Reis research fellowship.

\section{References}

Adler, N. E., Erselius, L. J., Chacón, M. G., Flier, W. G., Ordoñez, M. E., Kroon, L. P. N. M., et al. (2004). Genetic diversity of Phytophthora infestans sensu lato in Ecuador provides new insight into the origin of this important plant pathogen. Phytopathology, 94, 154-162.

Carter, D. A., Archer, S. A., Buck, K. W., Shaw, D. S., \& Shattock, R. C. (1990). Restriction fragment length polymorphisms of mitochondrial DNA of Phytophthora infestans. Mycological Research, 94, 1123-1128.

Cooke, D. E., Cano, L. M., Raffaele, S., Bain, R. A., Cooke, L. R., Etherington, G. J., et al. (2012). Genome analyses of an aggressive and invasive lineage of the Irish potato famine pathogen. PLOS Pathogens, 8, e1002940. www.plospathogens.org.

Cooke, D. E. L., \& Lees, A. K. (2004). Markers, old and new, for examining Phytophthora infestans diversity. Plant Pathology, 53, 692-704.

Deahl, K. L., Inglis, D. A., \& Demuth, S. P. (1993). Testing for resistance to metalaxyl in Phytophthora infestans isolates from northwestern Washington. American Potato Journal, 70, 779-795.

Deahl, K. L., Pagani, M. C., Vilaro, F. L., Perez, F. M., Moravec, B., \& Cooke, L. R. (2003). Characteristics of Phytophthora infestans isolates from Uruguay. European Journal of Plant Pathology, 109, 277-281.

Forbes, G. A., Escobar, X. C., Ayala, C. C., Revelo, J., Ordóñez, M. E., Fry, B. A., et al. (1997). Population genetic structure of Phytophthora infestans in Ecuador. Phytopathology, 87, 375-380.

Forbes, G. A., Goodwin, S. B., Drenth, A., Oyarzun, P., Ordoñez, M. E., \& Fry, W. E. (1998). A global marker database for Phytophthora infestans. Plant Disease, 82, 811-818.

Fry, W. E., \& Goodwin, S. B. (1997). Re-emergence of potato and tomato late blight in the United States. Plant Disease, 87, 1349-1357.

Fry, W. E., Goodwin, S. B., Matuszak, J. N., Spielman, L. J., Milgroom, M. G., \& Drenth, A. (1992). Population genetics and intercontinental migrations of Phytophthora infestans. Annual Review of Phytopathology, 30, 107-129.
Gallegly, M. E., \& Galindo, J. (1958). Mating types and oospores of Phytophthora infestans in nature in Mexico. Phytopathology, 48, 274-277.

Garry, G., Forbes, G. A., Salas, A., Santa Cruz, M., Perez, W. G., \& Nelson, R. J. (2005). Genetic diversity and host differentiation among isolates of Phytophthora infestans from cultivated potato and wild solanaceous hosts in Peru. Plant Pathology, 54, 740-748.

Gavino, P. D., \& Fry, W. E. (2002). Diversity in and evidence for selection on the mitochondrial genome of Phytophthora infestans. Mycologia, 94, 781-793.

Gavino, P. D., Smart, C. D., Sandrock, R. W., Miller, J. S., Hamm, P. B., Lee, T. Y., et al. (2000). Implications of sexual reproduction for Phytophthora infestans in the United States: Generation of an aggressive lineage. Plant Disease, 84, 731-735.

Goodwin, S. B. (1997). The population genetics of Phytophthora. Phytopathology, 87, 462-473.

Goodwin, S. B., Cohen, B. A., \& Fry, W. E. (1994). Panglobal distribution of a single clonal lineage of the Irish potato famine fungus. Proceedings of the National Academy of Sciences USA, 91, 11591-11595.

Griffith, G. W., \& Shaw, D. (1998). Polymorphisms in Phytophthora infestans: four mitochondrial haplotypes are detected after PCR amplification of DNA from pure cultures or from host lesions. Applied and Environmental Microbiology, 64, 4007-4014.

Hohl, H. R., \& Iselin, K. (1984). Strains of Phytophthora infestans from Switzerland with A2 mating type behaviour. Transactions of the British Mycological Society, 83, 529531.

Jones, J. B., Jones, J. P., Stall, R. E., \& Zitter, T. A. (1991). Compendium of tomato diseases. St. Paul, MN, USA: APS Press.

Judelson, H. S. (1996). Chromosomal heteromorphism linked to the mating type locus of the oomycete Phytophthora infestans. Molecular General Genetics, 252, 155-161.

Mizubuti, E. S. G. (2001). Requeima ou mela da batata e do tomate. In E. D. N. Luz, A. F. Santos, K. Matsuoka, \& J. L. Bezerra (Eds.), Doenças causadas por Phytophthora no Brasil (pp. 100-174). Campinas, SP, Brazil: Editora Rural.

Reis, A., Ribeiro, F. H. S., Maffia, L. A., \& Mizubuti, E. S. G. (2005). Sensitivity of Brazilian isolates of Phytophthora infestans to commonly used fungicides in tomato and potato crops. Plant Disease, 89, 1279-1284.

Reis, A., Ribeiro, F. H. S., \& Mizubuti, E. S. G. (2006). Caracterização de isolados de Phytophthora infestans do Distrito Federal e de Goiás. Fitopatologia Brasileira, 31, 270-276.

Reis, A., Smart, C. D., Fry, W. E., Maffia, L. A., \& Mizubuti, E. S. G. (2003). Characterization of isolates of Phytophthora infestans from southern and southeastern regions of Brazil, from 1998 to 2001. Plant Disease, 87, 896-900.

Ristaino, J. B. (2002). Tracking historic migrations of the Irish potato famine pathogen Phytophthora infestans. Microbes and Infection, 4, 1369-1377.

Ristaino, J. B., Hu, C. H., \& Fitt, B. D. L. (2012). Evidence for presence of the founder Ia mtDNA haplotype of Phytophthora infestans in 19th century potato tubers from the Rothamsted archives. Plant Pathology, 61, 1-9. 
Stevenson, W. R., Loria, R., Franc, G. D., \& Weingartner, D. P. (2001). Compendium of potato diseases. St. Paul, MN, USA: APS Press.

Suassuna, N. D., Maffia, L. A., \& Mizubuti, E. S. G. (2004). Aggressiveness and host specificity of Brazilian isolates of Phytophthora infestans. Plant Pathology, 53, 405-413.

Therrien, C. D., Tooley, P. W., Spielman, L. J., Fry, W. E., Ritch, D. L., \& Shelly, S. E. (1993). Nuclear DNA content, allozyme phenotypes and metalaxyl sensitivity of Phytophthora infestans from Japan. Mycological Research, 97, 945-950.

Vargas, A. M., Quesada Ocampo, L. M., Céspedes, M. C., Carreño, N., González, A., Rojas, A., et al. (2009). Characterization of Phytophthora infestans populations in Colombia: First report of the A2 mating type. Phytopathology, 99, 82-88. 